\title{
Ad fontes
}

\author{
Til eksamen i psykiatri leverte han Ibsens Terje Vigen - samtlige 43 vers lært utenat for anled- \\ ningen - med diagnostiske koder på hele persongalleriet. Medisinstudiet fortonet seg som en \\ ørkenvandring for Gunnar Grøstad Johnson. Kilden til glede i faget fant han først som all- \\ mennlege i distrikt.
}

«Vi befinner oss i hjertet av Vest-Telemark, i det området som inntil moderne tid bare har vært som en hvit flekk på kartet. Midt i landet, men fjernt fra sentrale strøk slik det vanligvis regnes.» Slik åpner Gunnar Grøstad Johnsons kortroman Perpeetum Mobile, trykt i Tokke historielags årsskrift 2007. Romanen handler om den oppdiktede, men for innvidde lett gjenkjennelige, Olaf N. Bjaaland i Lårdal og hans kraftverk. Grunntemaet er kampen mellom tradisjon og modernitet, vern og fremskritt, utvikling og forfall.

- Jeg har glede av å formulere meg, sier han. Bak dette utsagnet ligger utallige bidrag i lokalhistorisk sammenheng, minst ett upublisert skuespill, dikt og salmer. Han kan dertil gjøre seg forstått - eksempelvis om olympiske vintersportsgrener - på japansk.

Vi befinner oss altså denne sprengkalde, stjerneklare kvelden i hjertet av Vest-Telemark, i distriktet jeg selv kom til som en urban eksilant for 30 år siden, i bygda Mo i Tokke kommune. Riktignok ble det flere hundre kvadratmeter verneverdig prestegård med tilhørende herligheter og forvaltningsansvar på Gunnar Grøstad Johnson, ikke småbruk i Lårdal, slik han opprinnelig hadde tenkt seg da han søkte kommunelegestilling i Tokke etter turnus. Han fikk ikke jobben. Bakgrunnen for avslaget var hans konsekvente abortsyn og deravfølgende praksis som ikke bare omfatter selve abortprosessen, men også prevensjonsmetoder som potensielt kan føre til at et befruktet egg går til grunne.

- Jeg skriver ut p-piller, men ikke som prevensjon. Det tok meg noe tid å krystallisere ut det standpunktet, men min praksis er en logisk konsekvens av mitt syn på at livet begynner med det nye genomet.

\section{Kontrakten}

Vi må starte her. Det er vel kjent for mange av Tidsskriftets lesere at intervjuer og intervjuobjekt står på hver sin side i en til dels opphetet debatt om reservasjonsrett for leger på samvittighetsgrunnlag. Det er også derfor jeg ønsker å yte ham rettferdighet ved å synliggjøre ham i større bredde og en videre kontekst. Kanskje håper jeg også å løfte frem den dannelsen som består i å samtale åpent om grunnleggende spørsmål uten å skape fiendebilder eller hat, selv om de samtalende ikke kommer til samme konklusjon. Gunnar Grøstad Johnson har fått mye uønsket og på et vis ufortjent oppmerksomhet for sitt abortstandpunkt. Når jeg skriver ufortjent er det fordi han - ulikt de fleste kolleger som praktiserer slik han gjør - faktisk har redegjort for sine avgrensninger i forkant av kontraktsinngåelse med en oppdragsgiver, i dette tilfelle Vinje kommune. Han har aldri ønsket å statuere et eksempel eller være en flaggheiser. Vinje

\section{«Hvis det å gå til kildene - ad fontes - gjør meg til fundamentalist, så vær så god!»}

kommune tok selv kontakt og ba ham søke stillingen som kommunelege etter at nabokommunen Tokke hadde gitt ham avslag. I hans kommunale arbeidskontrakt er det gjort eksplisitt hvilke premisser som gjelder. Det var også arbeidsgiveren som ba Gunnar Grøstad Johnson betjene kontoret i Edland som eneste lege tre dager i uken, 45 kilometer fra det kommunale legesenteret i Åmot der han jobber resten av tiden. Han trives som del av et lite og tett førstelinjeteam i Edland, «en distriktsalveol» kaller han det.

- Hvilke tanker gjør du deg når jeg bruker begrepet samfunnskontrakten mellom leger i den offentlige helsetjenesten og deres avtalepartnere? Og hevder at du - eller i ditt tilfelle Vinje kommune - øver vold på den kontrakten ved å sette din egen samvittighet over lovhjemlede pasientrettigheter?

- I utgangspunktet har jeg signert bare én kontrakt, med Vinje kommune. Den oppfyller jeg. Kommunen ivaretar sine interesser gjennom et flerlegesamarbeid i den grad det er oppgaver jeg ikke kan tilby. Av usignerte kontrakter jeg føler meg forpliktet på, er en kontrakt hjemlet i legeetikken som settes i kraft hver gang jeg tar en pasient $i$ behandling. Du kan derfor kanskje si at det er like mange slike uskrevne kontrakter som jeg har pasienter. Alle disse kontraktene har jeg frem til i dag overholdt på en forskriftsmessig måte.

Nå forteller man meg at jeg også er forpliktet på en samfunnskontrakt. Samfunnskontrakten i myndighetenes retorikk bygger på norsk lovverk. Norske myndigheter styrer landet etter en konsensusetikk som innebærer at alt flertallet fremholder som etisk, er etisk. Det er en slik flertallsetikk som er uttrykt i våre lover. Det er imidlertid ikke nødvendigvis sammenfall mellom denne konsensusetikken og legeetikken. Norske legers arbeid hviler primært på legeetikken, sekundært på norske lover. - Hva betyr det for ditt standpunkt at du er katolikk?

- Vi konverterte til katolisismen etter at jeg fikk jobben i Vinje. Den aktuelle debatten var nok en utløsende faktor, selv om jeg i økende grad hadde kjent meg fremmedgjort i den norske statskirken. Jeg trengte den katolske kirkens ryggdekning. Det er godt ikke alltid å måtte forklare hva jeg personlig tror på, men være del av et større fellesskap på tvers av tid og rom.

\section{Forvalteren}

Samlingspunktet for katolikkene i VestTelemark ble, som resultat av Gunnars og hans kone Ingrid Grøstad Johnsons engasjement, flyttet til Mo. Vår Frue katolske menighet leier kirken til messe en gang $i$ måneden. Etterpå er det kirkekaffe i prestegården. Sambygdinger kan fortelle om en raus og inkluderende familie som i kvantitet, men enda mer i kvalitet utgjør et betydelig bidrag til et lite bygdesamfunn. Under Gunnar Grøstad Johnsons ledelse har bygdelaget bygd bro over den gamle fløtningsdammen i Mosvatn som forbinder de to sidene av bygda. Til våren starter arbeidet med å gruse den gamle kirkeveien der utsikten har begeistret kjente størrelser som Moltke Moe, Henrik Sørensen og Harald Kihle. I valgkretsen bor det kanskje et hundretalls mennesker, i sentrum under 50. Familien Grøstad Johnson venter i skrivende stund sitt femte barn. 


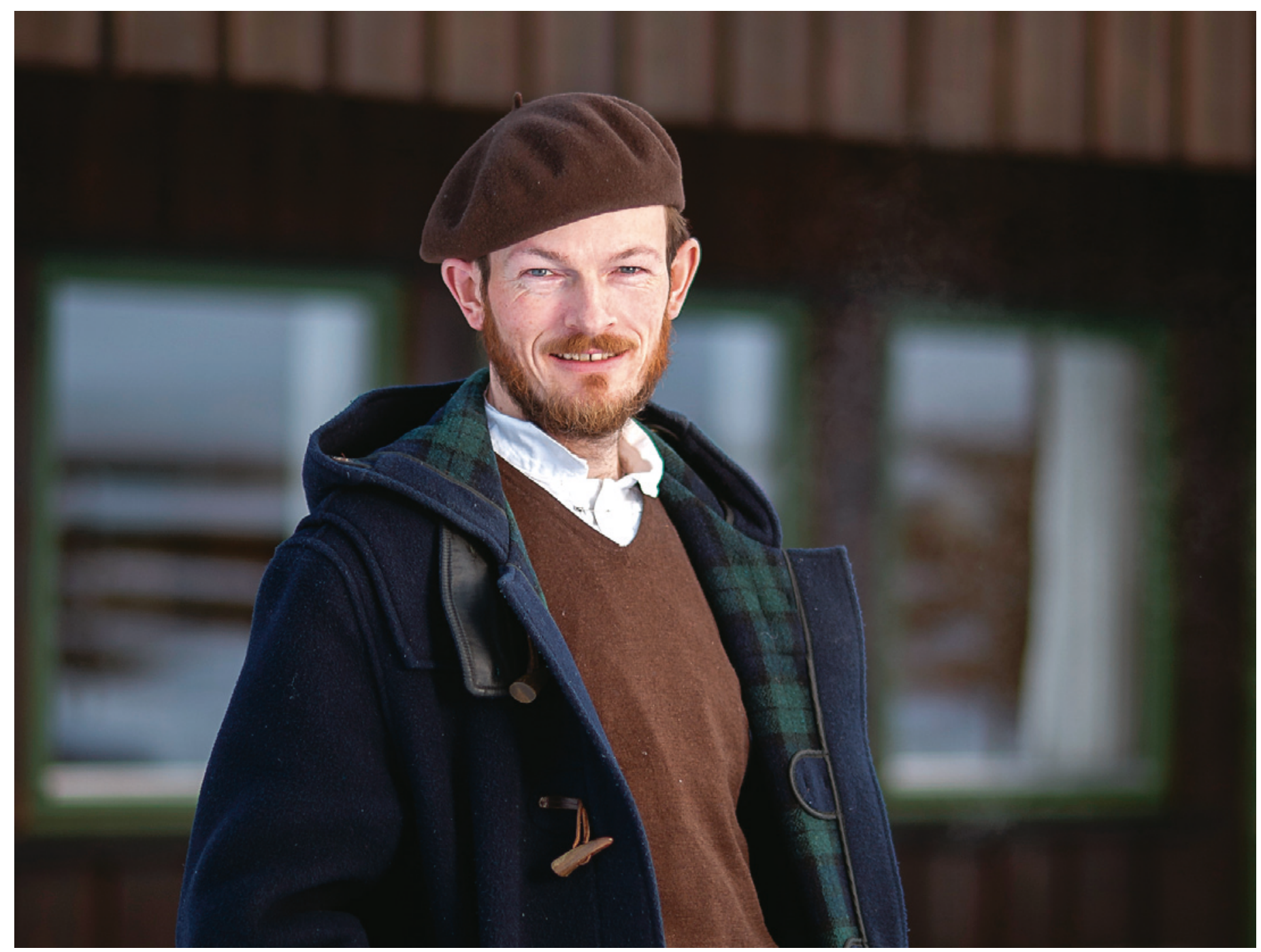

\section{Gunnar Grøstad Johnson}

\section{Født i Drammen 1970}

- Storfag japansk i Oslo 1993

- Cand.med. i Oslo 2004

- Japansklærer Oslo Handelsgymnasium 1993-96

- Jordbrukserfaring Hurum 2001-02

- Fastlege i Vinje kommune fra 2008
- Hvis det faller seg slik så får du kanskje med deg en hjemmefødsel, sier han når jeg ringer for å gjøre intervjuavtalen. Nærmeste fødeavdeling ligger 15 glatte, grisgrendte mil unna.

- Ja, jeg synes det blir for langt å reise, sier Ingrid Grøstad Johnson. Jon (7), Rosa (6), Lavrants (4) og Per (3) er vant til å ha mor hos seg. Dessuten gikk det greit å føde hjemme sist. Jeg kommer på historien om Jørgen Tjønnstaul, kjent spelemann fra Rauland, som én eneste gang tok turen til hovedstaden. «Det var fint i Oslo, men det låg noko avsides,» sa Jørgen etterpå.

Familien har noe sånt som tyve hus å passe på. De fikk kjøpe prestegården fra 1840, i mange år ubebodd, fordi de uten å blunke aksepterte premisset som selger formidlet om «evig buplikt». Det finnes selvsagt ikke noe slikt. Gunnar Grøstad Johnson er likevel innforstått med det livsvarige utgangspunktet. Hans kone står som driver og utvikler av inntektsgivende pro- sjekter på gården. Selvhusholdning er et mål. Familien får arbeidshjelp av folk som jobber mot kost og losji i kortere eller lengre perioder. For tiden bor Daniel og Lisa her, han hestebonde med lang erfaring, hun på ystekurs i Undredalen den dagen jeg er på besøk.

- Mo gamle prestegård drives etter mottoet «vern gjennom bruk». Vi har derfor pusset opp bare det høyst nødvendige, og lært å sette pris på patina og forfallets estetikk. Gården vi tok over var gjengrodd og nedslitt, men bar sin situasjon med verdighet. Da vi kom, måtte vi hugge frem flaggstangen. Hovedhuset har fått tette vinduer og er malt utvendig. Arbeidet innvendig tar vi rom for rom. Vi hadde i utgangspunktet ingen samfunnstanke med dette. Vi lette etter et sted å oppdra våre barn $i$ fred og i en kristen ånd, uten alle de duellene med sekulariteten som slike som oss råker ut for i dag. Nå kappes nye planer om å få mer av vår tid og innsats. Daniel har lagt 
planer for å ta i bruk hesteredskaper og gammelt utstyr som er samlet på gården. Konsekvensen blir at driften må bli den samme typen drift som har vært her for hundre år siden eller mer, altså tømmerdrift med hest, høyproduksjon for hånd eller med enkle

\section{«Jeg har praktisert aikido, båtbygging og bokbinding som del av min dannelsesreise»}

hesteredskaper, setting av hesjer, dyrking av poteter og hold av kyr og sau. Er dette et samfunnsoppdrag? Ikke vet jeg, men vi ønsker å ta vare på gammel kunnskap som kanskje en gang kan komme til nytte igjen. Lokale folk viser oss tillit på grunn av denne erklærte hensikten å bli i bygda.

\section{Homo universalis}

Han er barn av et legeektepar. I løpet av oppveksten flyttet familien flere ganger. Det er ikke eiendom til jord eller stedbundethet som har preget Gunnar Grøstad Johnsons slekt.

- Vår bunad har vært prestekragen, sier han. Hans tippoldefar var den legendariske lutheranske kjempen, professor Gisle Johnson. Apropos duellen med sekulariteten i sin samtid, som åpenbart må ha gått i arv. Kanskje gjelder det samme for kampviljen. Det går opp for meg i løpet av samtalen at han har en uvanlig bredde i sitt kunnskapstilfang. Ikke alt har kommet til ham i gode dager. Gunnar Grøstad Johnson er beskjeden om egne meritter og redd for å overlesse intervjuet med uvesentligheter. Jeg synes ikke det er uvesentlig at det ligger en Arendalssjekte i tunet - antagelig ikke ulik den Terje Vigen rodde - selvbygd, med håndverktøy. Eller at han behersker den japanske kampkunsten aikido. Og kan binde inn bøker. For den saks skyld heller ikke at han har vært norsk-japansk tolk under de olympiske vinterlekene på Lillehammer og i Nagano.

- Det er ikke du som skryter, Gunnar, det er jeg som spør.

- OK. Jeg kan jo likevel ikke fornekte fortiden. Du kan si at jeg har praktisert aikido, båtbygging og bokbinding som del av min dannelsesreise. Alle tre gir meg stor glede fremdeles, aikido i vedhogsten, båten under turer med barna på Vinjevatn, og bokbindingen for å vedlikeholde boksamlingen i prestegården.

Skolen husker han med liten glede. Det er en retrospektiv erkjennelse. Han spurte en gang om faren trodde han var hyperaktiv. Far sa nei. I dag bruker Gunnar Grøstad Johnson ordet «uforløst».

- Du kan vel si at jeg er av dem som ble kvestet av norsk skole. Jeg husker en episode der vi skulle lære om reformasjonen. Vi hadde fått en ny historielærer som sto langt til venstre i politikken. Han tegnet et diagram med oppslutning om kristendommen langs y-aksen og tiden langs x-aksen. Så tok han fart og tegnet en nedadgående kurve som uheldigvis havnet under null. Da sa jeg bare: «Du er ikke litt tendensiøs nå, Henriksen?» Etter det havnet jeg på bakerste benk. Jeg sto nok opp for det jeg trodde på da også.

Etter videregående skole ville han bare vekk. Så langt som mulig. Japan passet bra. Familien hadde forbindelser, han fikk treffe høytstående personer og ble «båret på gullstol» som han selv sier. Tiden i Japan ga ham et nytt språk, nye kulturelle referanser og venner for livet. En av dem har vært tilbake og undervist barna i japansk i den gamle skolestua som nå er gjenskapt $i$ ett av rommene på gården.

På medisinstudiet noen år etter var det stadig mindre som ga en følelse av å bli løftet. Gunnar Grøstad Johnsons opplevelse var at han fikk stener for brød - intellektuelt, etisk og praktisk. Han kjempet, tvilte og meldte seg utmattet ut etter gynekologiterminen. Bekymrede venner rådet ham til å gå i terapi. Han valgte å ta jobb som griserøkter og landarbeider. Etter hvert krøp han tilbake til medisinstudiet, fortsatt i sterk tvil. «Jeg ble en svært dårlig student, jeg leste annenhver side.» Det var på denne tiden han skrev sitt skuespill Confessio Medicorum, formet som en dialog mellom pasienten og legen om de store dilemmaene knyttet til vitenskap, autoritet, tro og nestekjærlighet. Her følger et par løsrevne utdrag for å gi leserne en fornemmelse. Pasienten: «Doktor, jeg er syk og splittet. Mitt sinn har tenkt for meget over livet. Det stemmer ikke overens» (...) Legen: "En massiv projeksjon av egen angst rett inn i pasientens bedeblikk kan lindre noe sorg, og legens fangst er navn og cere, penger, god butikk!»

- Dialogen var et mentalhygienisk prosjekt som holdt meg intellektuelt stimulert midt i den medisinskfaglige tåkevandringen. I tillegg til å dikte fikk jeg låne nøkkel til byens kirke og øvde Bach på pianoet der.

Kortversjonen av hvordan det gikk, er at Gunnar Grøstad Johnson slet seg frem til avsluttende eksamen, strøk, feiret denne skjebnens ironi med en strålende fest, traff Ingrid og lot seg overtale av henne til å fullføre. Hun støttet ham også gjennom turnustiden på Rjukan der han for så vidt likte seg, men kom hjem og gråt de dagene det ble utført aborter på sykehuset.

- Er du en fundamentalist?

- Ordet brukes så lemfeldig. Hvis det å gå til kildene - ad fontes - gjør meg til fundamentalist, så vær så god! Det rører ikke ved min salighet.

\section{Den andre}

Det er noe med å være ventet. Da jeg kjørte opp i tunet - etter litt for sent å ha registrert et vennlig skilt om ikke å gjøre nettopp det - sto far og fire barn i døråpningen. Gjesten fikk tilbud om minst to par tøfler. Det trengs. Huset er kaldt og rommene høyloftede. Store lysekroner med levende lys hjelper. Ingrid serverte suppe og brød etter

\section{«Vi lette etter et sted å oppdra våre barn i fred og i en kristen ånd, uten alle de duellene med sekulariteten som slike som oss råker ut for i dag»}

at Per hadde fått velge bordvers og den uttalt sekulære gjesten hadde lært hvordan man korser seg. Først opp-ned, deretter venstre-høyre. Jeg fikk høre om skolen der Rosa og Jon er to av til sammen ni barn. Lavrants og jeg fant ut at jeg kjenner hans oldemor. Etterpå snakket vi voksne lenge mens barna fulgte oppmerksomt med.

- En familie som ikke har en utenforstående til bords blir lett høylytt og kranglevoren, sier Gunnar Grøstad Johnson.

På veien hjem tenkte jeg på det han fortalte meg om japanske brev. Tradisjonelt setter japanerne mottakerens navn der vi signerer med vårt eget.

Det gjør noe med forståelsen av relasjoner.

Elisabeth Swensen

elswense@online.no

Tidsskriftet 